\title{
Isotope effects between hydrogen and deuterium microwave plasmas on chemical vapor deposition homoepitaxial diamond growth
}

\author{
N. Mizuochi ${ }^{a}$ and J. Isoya \\ Diamond Research Center, AIST, Tsukuba Central 2, Tsukuba, 305-8568, Japan; \\ Graduate School of Library, Information and Media Studies, University of Tsukuba, \\ Tsukuba, 305-8550, Japan; and CREST JST, Chiyoda Tokyo, 102-0081, Japan \\ J. Niitsuma and T. Sekiguchi \\ National Institute for Materials Science, Tsukuba, 305-0044, Japan \\ H. Watanabe, H. Kato, T. Makino, H. Okushi, and S. Yamasaki \\ Diamond Research Center, AIST, Tsukuba Central 2, Tsukuba, 305-8568, Japan \\ and CREST JST, Chiyoda Tokyo, 102-0081, Japan
}

(Received 15 January 2007; accepted 6 March 2007; published online 16 May 2007)

\begin{abstract}
This article shows that replacing hydrogen with deuterium improves the quality of microwave plasma-assisted chemical vapor deposition homoepitaxial diamond. Suppression of point defects in the bulk and of nonepitaxial crystallites and increasing of free-exciton emission intensity were revealed by electron paramagnetic resonance, optical microscopy, and cathodoluminescence, respectively. The isotope effects on the etching rate of diamond by deuterium are also revealed. The isotope effects are discussed from the viewpoint of etching effects. (C) 2007 American Institute of Physics. [DOI: 10.1063/1.2727380]
\end{abstract}

\section{INTRODUCTION}

Diamond has attracted significant interest as material for optical devices in the ultraviolet light emission regime and for high-power and high-frequency devices because of its superior physical and electrical properties. ${ }^{1}$ Recently, highquality diamond films with high Hall mobility ${ }^{2-4}$ and high growth rate ${ }^{5-7}$ are synthesized in microwave plasma-assisted chemical vapor deposition (MPCVD). Further improvements require the suppression of residual impurities and defects such as nonepitaxial crystallites (NC) and carbon dangling bond defects accompanying hydrogen atom $\left(\mathrm{H} 1^{\prime}\right)$, because these defects extensively influence diamond's electrical and optical properties. ${ }^{8-10}$

In CVD techniques, diamond is grown by hydrocarbon species predominantly composed of hydrogen $\left(\mathrm{H}_{2}\right)$. In plasma, electron impact with $\mathrm{H}_{2}$ produces atomic hydrogen $(\mathrm{H})$. It is well known that $\mathrm{H}$ plays important roles in the growth of high-quality diamond. ${ }^{11}$ One of them is etching. It was previously reported that $\mathrm{H}$ selectively etches nondiamond-bonded material and graphite. ${ }^{11}$ A theoretical study reports that $\mathrm{H}$ preferentially removes $\mathrm{CH}_{2}$ moiety from the terrace of the (001) surface, promoting growth at steps (or kinks) and deposition of a smooth surface. ${ }^{12}$ Promoting these effects is expected to improve quality.

Replacing $\mathrm{H}_{2}$ with deuterium $\left(\mathrm{D}_{2}\right)$ reportedly increases the plasma etching rate in crystalline $\mathrm{Si}^{13}$ reduces lightinduced degradation in amorphous $\mathrm{Si}^{14}{ }^{14}$ and increases resistance of Si-D bond breaking above that of $\mathrm{Si}-\mathrm{H}$ bonds at the Si surface and the $\mathrm{Si} / \mathrm{SiO}_{2}$ interface. ${ }^{15}$ MPCVD diamond films have been grown using $\mathrm{D}_{2}$ to investigate the spatial distribution of $\mathrm{D}$ in the bulk of diamond ${ }^{16}$ or to assign vibra-

${ }^{a)}$ Electronic mail: mizuochi@slis.tsukuba.ac.jp tional frequency of C-H bonds. ${ }^{17}$ However, isotope effects on MPCVD diamond growth have not been studied so these effects are the theme of this study.

\section{EXPERIMENT}

Diamond films were deposited epitaxially on highpressure and high-temperature (HPHT) IIa and HPHT Ib single crystalline diamond (001) substrates with dimensions of $2.5 \times 2.5 \times 0.5 \mathrm{~mm}^{3}$ and $3.0 \times 3.0 \times 0.5 \mathrm{~mm}^{3}$, respectively (Sumitomo Electric Industries Ltd.). Their misorientation angles from (100) axis are shown in Table I. One benefit of a IIa substrate is that it prevents an overlap of strong electron paramagnetic resonance (EPR) signals of nitrogen. The films were grown in a MPCVD reactor using $\mathrm{CH}_{4}$ (or $\mathrm{CD}_{4}$ ) diluted with $\mathrm{H}_{2}$ (or $\mathrm{D}_{2}$ ) purified to more than $99.9999999 \%$ by a diffusion purifier (Japan Pionics Co. Ltd.). The substrate temperature was controlled by high-frequency heater independently of the input microwave (MW) power and kept at $1073 \mathrm{~K}$ as measured by a thermocouple attached to the backside of a susceptor. The total gas pressure, total gas flow rate,

TABLE I. The growth conditions, $\mathrm{NC}$ densities, and $\mathrm{C}_{\mathrm{H} 1^{\prime}}$.

\begin{tabular}{ccccccc}
\hline \hline Film & Gas & Type & $\theta_{\text {off }}{ }^{2}$ & Growth rate & NC density & $\mathrm{C}_{\mathrm{H}^{\prime}} / \mathrm{cm}^{3}$ \\
\hline D-I & $\mathrm{CD}_{4} / \mathrm{D}_{2}$ & IIa & $4 \pm 1^{\circ}$ & & $<10^{3} / \mathrm{cm}^{2}$ & $(6 \pm 3) \times 10^{16}$ \\
D-II & $\mathrm{CD}_{4} / \mathrm{D}_{2}$ & IIa & $4 \pm 1^{\circ}$ & & $<10^{3} / \mathrm{cm}^{2}$ & $(2 \pm 1) \times 10^{17}$ \\
D-III & $\mathrm{CH}_{4} / \mathrm{D}_{2}$ & IIa & $4 \pm 1^{\circ}$ & & $<10^{3} / \mathrm{cm}^{2}$ & $(1 \pm 0.5) \times 10^{17}$ \\
D-IV & $\mathrm{CD}_{4} / \mathrm{D}_{2}$ & Ib & $<1^{\circ}$ & $0.12 \mu \mathrm{m} / \mathrm{h}$ & $<10^{3} / \mathrm{cm}^{2}$ & \\
D-V & $\mathrm{CH}_{4} / \mathrm{D}_{2}$ & Ib & $<1^{\circ}$ & $0.13 \mu \mathrm{m} / \mathrm{h}$ & $<10^{3} / \mathrm{cm}^{2}$ & \\
\hline $\mathrm{H}$-VI & $\mathrm{CH}_{4} / \mathrm{H}_{2}$ & IIa & $4 \pm 1^{\circ}$ & & $10^{4}-10^{5} / \mathrm{cm}^{2}$ & $(4 \pm 2) \times 10^{18}$ \\
H-VII & $\mathrm{CH}_{4} / \mathrm{H}_{2}$ & IIa & $4 \pm 1^{\circ}$ & & $10^{4}-10^{5} / \mathrm{cm}^{2}$ & $(4 \pm 2) \times 10^{18}$ \\
H-VIII & $\mathrm{CH}_{4} / \mathrm{H}_{2}$ & Ib & $<1^{\circ}$ & $0.27 \mu \mathrm{m} / \mathrm{h}$ & $10^{4}-10^{5} / \mathrm{cm}^{2}$ & \\
\hline
\end{tabular}

${ }^{\mathrm{a}} \theta_{\text {off }}$ is misorientation angle from (001) axis.

${ }^{\mathrm{b}}$ The experimental error of the estimation is less than $10 \%$. 


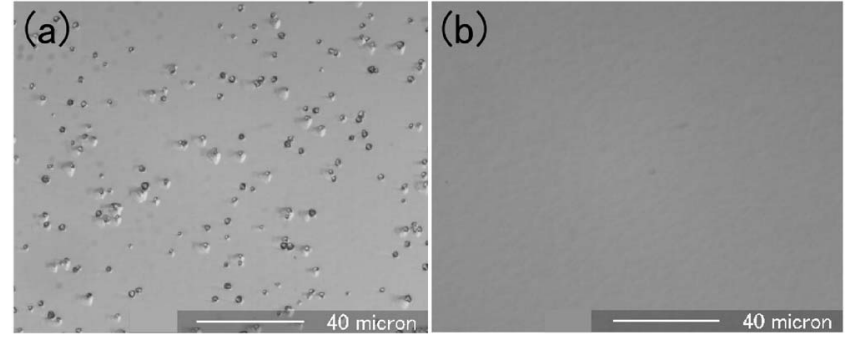

FIG. 1. The OM images of films grown by using (a) $\mathrm{H}_{2}(\mathrm{H}-\mathrm{VI})$ and (b) $\mathrm{D}_{2}$ (D-V).

and input MW power were maintained constant at 25 Torr, $400 \mathrm{sccm}$, and $750 \mathrm{~W}$, respectively. Deposition durations and $\mathrm{CH}_{4}\left(\mathrm{CD}_{4}\right) / \mathrm{H}_{2}\left(\mathrm{D}_{2}\right)$ ratios were $6 \mathrm{~h}$ and $0.5 \%$, respectively. The thicknesses of films labeled D-IV, D-V, H-VIII were estimated by secondary ion mass spectroscopy (SIMS) or the step height between the substrate regions with and without a diamond mask. The thicknesses of films labeled D-I-III, H-VI-VII were simply estimated by deposition durations using the thickness data of films D-IV, D-V, H-VIII.

EPR spectra were measured by a Bruker ELEXSYS $X$-band spectrometer with a He cryostat. The CL measurements were performed at $200 \mathrm{~K}$ and acceleration voltages of 7 and $10 \mathrm{keV}$, which correspond to electron penetration depths of about 0.5 and $0.9 \mu \mathrm{m}$, respectively. ${ }^{18}$ The details of the EPR and CL measurements are described elsewhere. ${ }^{9,19}$ Optical emission spectra (OES) were obtained by using a charge-coupled device (CCD) detector. The emission light from the plasma was focused by a lens which is fixed to the MPCVD reactor. The focused light was transmitted by optical fiber with resolution of $2.1 \mathrm{~nm}$ to the CCD detector.

For estimation of etching rates, HPHT Ib single crystalline (100) diamond was etched by inductively coupled plasma (ICP) (ULVAC Inc.). The power, bias voltage, pressure, and etching duration were $1 \mathrm{~kW}, 0 \mathrm{~V}, 4 \mathrm{~Pa}$, and $4.5 \mathrm{~h}$, respectively. As a mask of diamond etching, Au layers of $0.2 \mu \mathrm{m}$ thickness were deposited by electron beam evaporation method. Au layers were removed by acid treatment after the etching. The etching rates were estimated by measuring a bump height between the Au covered surface and etched surface by stylus profiler (Dektak 8, Veeco Instruments).

\section{RESULTS AND DISCUSSION}

Using optical microscopy (OM) and EPR, we investigated $\mathrm{NC}$ and $\mathrm{H} 1^{\prime}$ respectively, in films grown by $\mathrm{CD}_{4} / \mathrm{D}_{2}$, $\mathrm{CH}_{4} / \mathrm{D}_{2}$, and $\mathrm{CH}_{4} / \mathrm{H}_{2}$. Figure 1 shows $\mathrm{OM}$ images of films. The NC densities are summarized in Table I, which shows that replacing $\mathrm{H}_{2}$ with $\mathrm{D}_{2}$ reduced the $\mathrm{NC}$ density by more than one order of magnitude.

The solid lines in Figs. 2(a) and 2(b) are EPR spectra of films grown by $\mathrm{CH}_{4} / \mathrm{H}_{2}(\mathrm{H}-\mathrm{VI})$ and $\mathrm{CD}_{4} / \mathrm{D}_{2}$ (D-II), respectively. The $g$-values were estimated at $2.0026 \pm 0.0001$. In H-VI, H1' was clearly observed. An EPR line shape with a pair of partly resolved satellite lines with splitting of 1.25 $\mathrm{mT}$, caused by the forbidden transitions of nearby $\mathrm{H}$, is a characteristic of $\mathrm{H} 1^{\prime}$ centers. ${ }^{19}$ In the previously reported films ${ }^{9,19}$ grown with the same condition of H-VI, the concentrations of $\mathrm{H}^{\prime}{ }^{\prime}\left(\mathrm{C}_{\mathrm{H} 1^{\prime}}\right)\left[(3-8) \times 10^{18} / \mathrm{cm}^{3}\right]$ are almost the

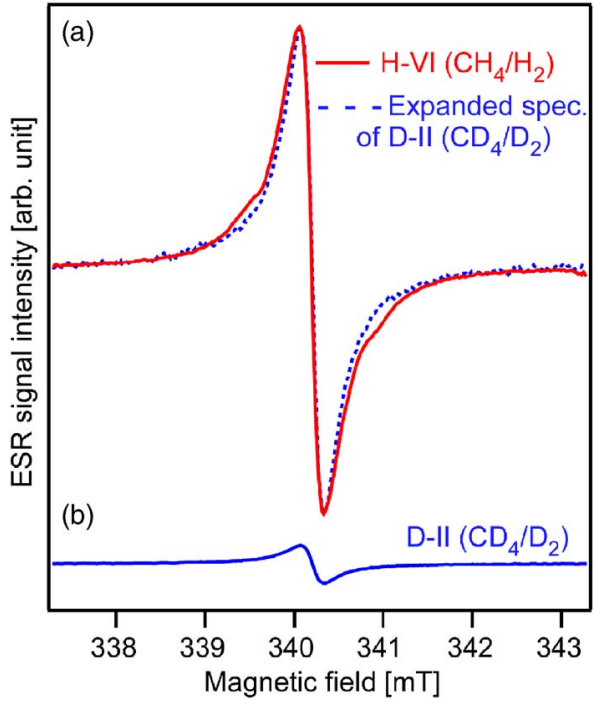

FIG. 2. (Color online) The EPR spectra in films (a) H-VI and (b) D-II at 40 $\mathrm{K}$. The MW frequencies are $9.45 \mathrm{GHz}$. The MW power and the amplitude of $100 \mathrm{kHz}$ field modulation were $0.1 \mathrm{~mW}$ and $0.07 \mathrm{mT}$, respectively. In (a), the signal intensity of film D-II (dotted line) is expanded to compare the EPR line shapes.

same as that of H-VI. It was clearly revealed that the defect concentration decreased more than 10 times by replacing $\mathrm{H}_{2}$ with $\mathrm{D}_{2}$ as shown in Fig. 2 and Table I.

In Fig. 2(a), the normalized spectrum of D-II grown by $\mathrm{CD}_{4} / \mathrm{D}_{2}$ is represented by a dotted line for comparison with the EPR line shapes. The $g$-value and the isotropic character of the spectra of D-I-III are identical to those of $\mathrm{H}^{\prime}{ }^{\prime}$. Figure 2(a) does not show the characteristic shoulder of $\mathrm{H}^{\prime}{ }^{\prime}$, which is reasonable where $\mathrm{H}$ is replaced with $\mathrm{D}$. The splitting of the forbidden transition is approximately represented as $2\left(g_{n} \mu_{n} / g_{e}^{2} \mu_{B}^{2}\right) h \nu,{ }^{19}$ where $g_{n}$ and $g_{e}$ are the nuclear and electronic $g$-values, respectively, $\mu_{n}$ and $\mu_{B}$ are corresponding Bohr magnetons, respectively, and $h$ and $\nu$ are Planck's constant and MW resonant frequency of EPR, respectively. When $\mathrm{H} \quad\left(g_{n}=5.5857\right)$ in $\mathrm{H}^{\prime}$ is replaced by $\mathrm{D}$ $\left(g_{n}=0.8574\right),{ }^{20}$ the splitting is calculated as about $0.2 \mathrm{mT}$, which can be hidden in the main peak. The SIMS measurement estimates the concentration of $\mathrm{D}$ in the film as 5 $-6( \pm 5) \times 10^{16} / \mathrm{cm}^{3}$ : almost identical to the spin concentration estimated from EPR. This suggests that the observed EPR signals in D-I-III mainly consists of that of $\mathrm{H}^{\prime}$, where $\mathrm{H}$ is replaced with $\mathrm{D}$, and that almost all $\mathrm{H}$ or $\mathrm{D}$ incorporated in our CVD diamond creates EPR active $\mathrm{H}^{\prime}$ ' centers, whereas negative charged states of H-vacancy complex are observed in $\mathrm{N}$-doped CVD diamond grown under high growth conditions. ${ }^{21}$

Figure 3(a) shows the CL spectra of films D-I and H-VI. The spectra are attributed to free-exciton emission associated with a transverse optical phonon $(235 \mathrm{~nm})$ and its replica $(242 \mathrm{~nm}){ }^{22}$ Figure 3(b) shows the free-exciton signal intensities $\left(I_{\mathrm{ex}}\right)$ of D-I-III and H-VI-VIII at $\lambda=235 \mathrm{~nm}$, indicating that $I_{\mathrm{ex}}$ of D-I-III using $\mathrm{D}_{2}$ is about 5 times larger than $I_{\text {ex }}$ of H-VI-VIII using $\mathrm{H}_{2}$ on average. Their ratios were almost the same between acceleration voltages of 7 and 10 $\mathrm{keV}$.

The growth rates of films D-IV, D-V, H-VIII are shown 

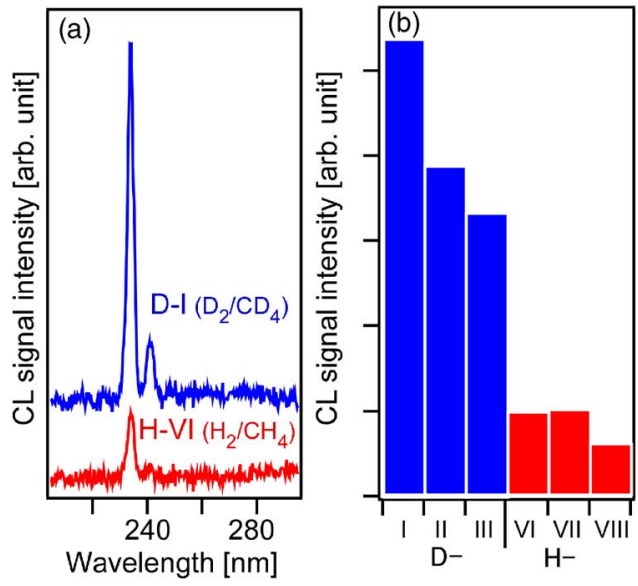

FIG. 3. (Color online) (a) The CL spectra of films D-I (upper) and H-VI (lower) at $100 \mathrm{~K}$. The acceleration voltages of $10 \mathrm{keV}$. (b) The integrated signal intensity of free exciton of films D-I $\left(\mathrm{CD}_{4} / \mathrm{D}_{2}\right), \mathrm{D}-\mathrm{II}\left(\mathrm{CD}_{4} / \mathrm{D}_{2}\right), \mathrm{D}$-III $\left(\mathrm{CH}_{4} / \mathrm{D}_{2}\right)$, and $\mathrm{H}-\mathrm{VI}\left(\mathrm{CH}_{4} / \mathrm{H}_{2}\right)$.

in Table I. The growth rate of $\mathrm{H}$-VIII grown by $\mathrm{CH}_{4} / \mathrm{H}_{2}$ is typical for this synthesis condition. ${ }^{19,22}$ These results indicate that the growth rate using $\mathrm{D}_{2}$ is almost half of that using $\mathrm{H}_{2}$. It was reported that $\mathrm{C}_{\mathrm{H} 1}$, decreases and $I_{\mathrm{ex}}$ increases as the growth rate decreases. ${ }^{1,9}$ In those results, when the growth rate is halved by the decrease of the $\mathrm{CH}_{4} / \mathrm{H}_{2}$ ratio, it can be extrapolated that $\mathrm{C}_{\mathrm{H} 1}$, decreases by half and about $80 \%$ of $I_{\mathrm{ex}}$ increases. If these quantities are subtracted from the total amounts of differences by replacing $\mathrm{H}_{2}$ with $\mathrm{D}_{2}$, the substantial improvements by the isotope effects are estimated to be the decrease of one order of $\mathrm{C}_{\mathrm{H} 1}$, and the approximately 3 times increase of $I_{\mathrm{ex}}$ on average. Within our systematic experiments, this difference of CL intensity is beyond the experimental errors.

Diamond synthesis is always a competition between deposition and etching. ${ }^{11,12,23}$ The slower growth rate using $\mathrm{D}_{2}$ can be assumed to be due to the higher etching effects of $\mathrm{D}$ compared with $\mathrm{H}$ as discussed in the following.

Isotope effects of electron- $\mathrm{H}_{2}$ collision processes such as excitation and dissociation have been reported. ${ }^{24-26}$ One theoretical study focused on the isotope effects on the dissociation process of $\mathrm{D}_{2}$ and $\mathrm{H}_{2}$ through the ground state $\left(X^{1} \Sigma_{g}^{+}\right)$to the first excited state $\left(b^{3} \Sigma_{u}^{+}\right)$including vibrational levels. ${ }^{24}$ Their calculations revealed a larger cross section of $\mathrm{D}_{2}$ than that of $\mathrm{H}_{2}$, because the density of the states of the dissociation channel differs between $\mathrm{H}_{2}$ and $\mathrm{D}_{2}$ due to the energy difference of their vibrational levels. Through this process, the concentration of $\mathrm{D}$ in the plasma will probably be larger than that of $\mathrm{H}$, which can promote the etching effect. We investigated the plasmas under our growth conditions by OES: a powerful technique for in situ diagnosis of plasma. ${ }^{27}$ Figure 4 shows the OES spectra of $\mathrm{H}_{2}$ and $\mathrm{D}_{2}$ plasmas with the same growth condition parameters without methane. The compositions of gases in each plasma are (a) $100 \% \mathrm{H}_{2}$; (b) $50 \% \mathrm{H}_{2}$ and $50 \% \mathrm{D}_{2}$; (c) $100 \% \mathrm{D}_{2}$; and (d) $100 \% \mathrm{H}_{2}$, respectively. They were measured consecutively from (a) to (d) only changing $\mathrm{H}_{2}$ and $\mathrm{D}_{2}$ without switching off the plasma. The Balmer lines labeled as $\mathrm{H}_{\alpha}\left(\mathrm{D}_{\alpha}\right)$ at $656 \mathrm{~nm}$ and $\mathrm{H}_{\beta}\left(\mathrm{D}_{\beta}\right)$ at $486 \mathrm{~nm}$ were observed. The wavelength differences of the Balmer lines between $\mathrm{H}$ and $\mathrm{D}$ are less than $0.2 \mathrm{~nm},{ }^{28}$ which

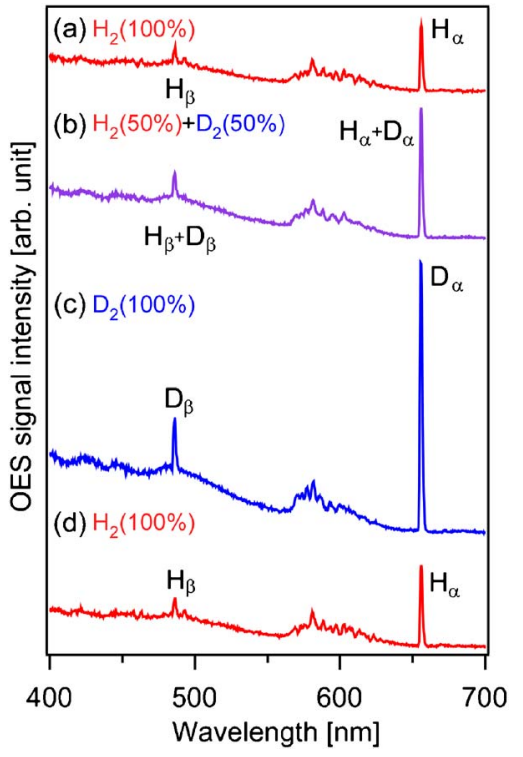

FIG. 4. (Color online) The OES spectra of $\mathrm{H}_{2}$ and $\mathrm{D}_{2}$ plasmas. The compositions of gases in each plasma are (a) $100 \% \mathrm{H}_{2}$; (b) $50 \% \mathrm{H}_{2}$ and $50 \% \mathrm{D}_{2}$; (c) $100 \% \mathrm{D}_{2}$; and (d) $100 \% \mathrm{H}_{2}$, respectively. These spectra were measured consecutively from (a) to (d) by only changing the gases without switching off the plasma.

was less than our resolution of $2.1 \mathrm{~nm}$. As Fig. 4 shows, the signal intensities significantly increased more than 4 times after $\mathrm{H}_{2}$ was replaced by $\mathrm{D}_{2}$. Replacing $\mathrm{D}_{2}$ by $\mathrm{H}_{2}$ returned the signal intensities to (a). Because the emission processes of $\mathrm{D}_{2}$ can be assumed to be the same as those of $\mathrm{H}_{2}$ in the present condition, the increase of the signal intensity suggests a higher concentration of $\mathrm{D}$ than that of $\mathrm{H}$.

Other studies have reported a larger cross section of the rotational excitation $\left(\tau_{R}\right)$ of $\mathrm{D}_{2}$ than that of $\mathrm{H}_{2} \cdot{ }^{22,23}$ Furthermore, $\tau_{R}$ of $J=0 \rightarrow 2$ is reportedly larger than $\tau_{R}$ of $J=1$ $\rightarrow 3$, where $J$ is rotational quantum number. From nuclear statistics, the ratio of ortho- $\mathrm{H}_{2}\left(o-\mathrm{H}_{2}\right)$ to para $-\mathrm{H}_{2}\left(p-\mathrm{H}_{2}\right)$ is $3: 1$, while the ratio of $o-\mathrm{D}_{2}$ to $p-\mathrm{D}_{2}$ is $1: 2$. From the quantum-mechanical requirements, $o-\mathrm{H}_{2}\left(\mathrm{D}_{2}\right)$ can only exist in odd- $J(J=1,3, \ldots)$ state and $p-\mathrm{H}_{2}\left(\mathrm{D}_{2}\right)$ can only exist in even- $J(0,2, \ldots)$ state. Based on these effects, $D_{2}$ is expected to gain higher energy than $\mathrm{H}_{2}$ in plasma, which can cause the energy of D to be higher than that with $\mathrm{H}$. During syntheses, the substrate temperature was controlled by high-frequency heater equipment, which is independent of the microwave power sustaining plasma, and kept at $1073 \mathrm{~K}$. In the syntheses by using $\mathrm{D}_{2}, 15 \%$ decrease of the power of the highfrequency heating for substrate was observed. This presumably shows higher energy of D compared with $\mathrm{H}$, which may further promote the etching effect.

It should be noted that a heat capacity $(C p)$ of $\mathrm{D}_{2}$ at 298 $\mathrm{K}$ is $29.19 \mathrm{~J} / \mathrm{mol} \mathrm{K}$ which is the same with that of $\mathrm{H}_{2}{ }^{29,30}$ Furthermore, $C p$ of atomic D is $20.8 \mathrm{~J} / \mathrm{mol} \mathrm{K}$ which is also the same as that of atomic $\mathrm{H}^{29,30}$

The thermal conductivities $(k)$ of $\mathrm{H}_{2}$ and $\mathrm{D}_{2}$ at $300 \mathrm{~K}$ are $\quad 4.529 \times 10^{-4} \mathrm{cal} \mathrm{cm}^{-1} \mathrm{~s}^{-1} \mathrm{~K}^{-1} \quad$ and $\quad 3.405$ $\times 10^{-4} \mathrm{cal} \mathrm{cm}^{-1} \mathrm{~s}^{-1} \mathrm{~K}^{-1}$, respectively. ${ }^{31}$ This indicates that the ability to transfer heat by $\mathrm{H}_{2}$ is slightly higher than that of $\mathrm{D}_{2}$. On the other hand, it is indicated that larger heat is transferred to the sample in the $\mathrm{D}_{2}$ synthesis compared with 


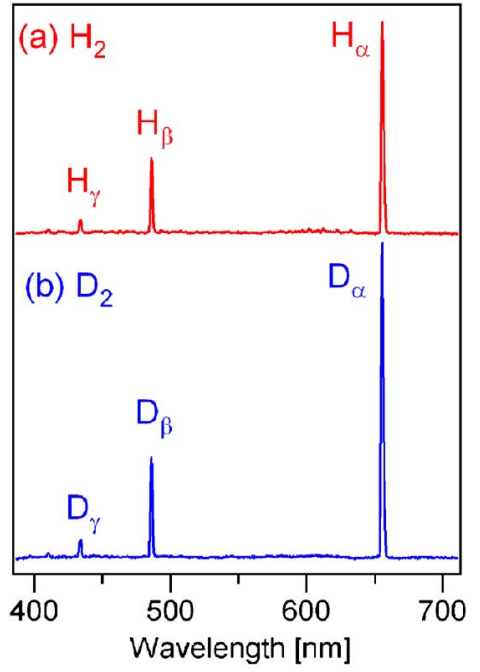

FIG. 5. (Color online) The OES spectra of (a) $\mathrm{H}_{2}$ and (b) $\mathrm{D}_{2}$ plasmas in the ICP.

that in the $\mathrm{H}_{2}$ synthesis from the observation of the smaller power for the heating of the substrate. These may also support that the energy of molecules and atoms in the $\mathrm{D}_{2}$ plasma is higher than those in the $\mathrm{H}_{2}$ plasma. For the quantitative prediction of how much the difference of $k$ contributes to the difference of the plasmas, further research is necessary.

Furthermore, we directly measured the etching rates of diamond by $\mathrm{H}_{2}$ and $\mathrm{D}_{2}$ in ICP etching. The OES spectra of the ICP are shown in Fig. 5. Similar to the spectra of Fig. 4, the emissions from $\mathrm{H}$ and $\mathrm{D}$ were observed. As seen from them, the signal intensity of D was about $30 \%$ stronger than that of H. Etching depths were measured as shown in Fig. 6. The bump heights by the etchings of $\mathrm{H}$ and $\mathrm{D}$ were estimated to be 400 and $480 \mathrm{~nm}$, respectively. From them, the etching rates by $\mathrm{H}$ and $\mathrm{D}$ were estimated to be 89 and $107 \mathrm{~nm} / \mathrm{h}$, respectively. This indicates that the etching rate by $\mathrm{D}$ is about 20\% larger than that by $\mathrm{H}$ in this condition.

Quantitatively, the etching rates in the MPCVD synthesis may be different from the ICP etching because of the difference of etching plasma conditions according to the difference of etching methods. In our conditions, the difference

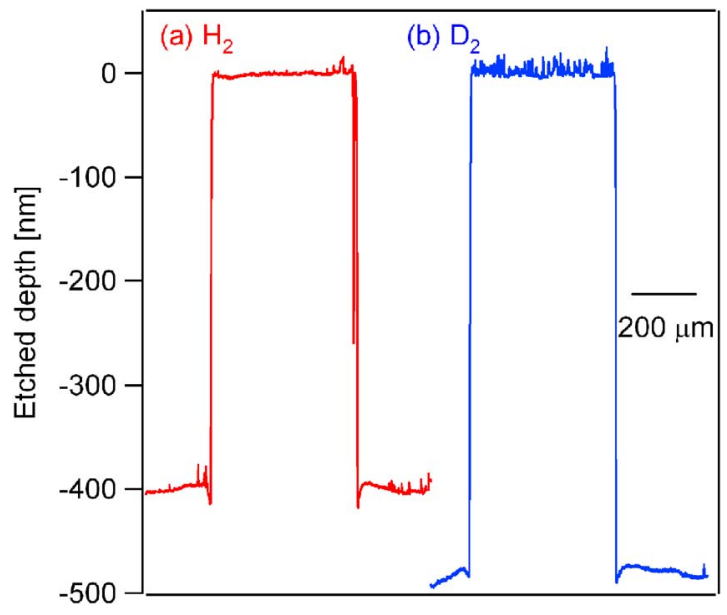

FIG. 6. (Color online) The etching depths by (a) $\mathrm{H}_{2}$ and (b) $\mathrm{D}_{2}$. Each center region is the Au covered region. of the OES signal intensity between $\mathrm{H}$ and $\mathrm{D}$ in the ICP etching was smaller than that of the MPCVD synthesis. It may be considered that the effects from the different dissociation processes with the calculated process through the ground state $\left(X^{1} \Sigma_{g}^{+}\right)$to the first excited state $\left(b^{3} \Sigma_{u}^{+}\right)$(Ref. 24) may be changed. If the etching rate can be assumed to be simply proportional to the relative OES signal intensity of $\mathrm{H}$ and $\mathrm{D}$, the ratio of the etching rate by $\mathrm{D}$ to the etching rate by $\mathrm{H}$ in the MPCVD synthesis is considered to be larger than in the ICP etching.

As for the etching by $\mathrm{D}$, it must have a different quality compared to the etching by $\mathrm{H}$ because the reduction in growth rate alone is apparently not sufficient to explain the data in this study. It can be supposed that the etching by D may promote the $\mathrm{H}$ etching effects for high-quality growth. $11,12,23$

It should be noted that the difference of bond dissociation energies between $\mathrm{H}_{2}$ and $\mathrm{D}_{2}$ is small. Their values of $\mathrm{H}_{2}$ and $\mathrm{D}_{2}$ are 435.990 and $443.533 \mathrm{~kJ} / \mathrm{mol}$, respectively. ${ }^{32}$ Similarly, the differences of it between C-H and that of C-D are small, w 338.4 and $341.4 \mathrm{~kJ} / \mathrm{mol}$, respectively. ${ }^{32}$ It should be noted that, as for the isotope effect on increase of the resistance of $\mathrm{Si}-\mathrm{D}$ bond breaking at $\mathrm{Si}$ surface and $\mathrm{Si} / \mathrm{SiO}_{2}$ interface, it is interpreted that the coupling of the Si-D bending mode to the Si bulk phonons results in an efficient channel for deexcitation. ${ }^{15,33}$ In diamond, as far as we know, such a correspondence of phonon frequencies is not reported. Therefore, the stability for C-D bond breaking at the surface can be considered to be almost the same as $\mathrm{C}-\mathrm{H}$ in diamond.

\section{SUMMARY}

The CVD homoepitaxial diamond films grown by $\mathrm{D}_{2}$ plasma were investigated by OM, EPR, and CL, revealing suppression of the defect density and the increase of $I_{\mathrm{ex}}$ by replacing $\mathrm{H}_{2}$ with $\mathrm{D}_{2}$. In the plasma of the present growth condition, higher concentration and higher energy of D compared with those of $\mathrm{H}$ are suggested, which can be considered to be the main sources of the isotope effect. From the ICP etching, the higher etching rate by $\mathrm{D}$ compared with that of $\mathrm{H}$ was demonstrated.

${ }^{1}$ H. Okushi, Diamond Relat. Mater. 10, 281 (2001).

${ }^{2}$ S. Yamanaka, H. Watanabe, S. Masai, D. Takeuchi, H. Okushi, and K. Kajimura, Jpn. J. Appl. Phys., Part 2 37, L1129 (1998).

${ }^{3}$ H. Kato, H. Okushi, and S. Yamasaki, Appl. Phys. Lett. 86, 222111 (2005).

${ }^{4}$ M. Katagiri, J. Isoya, S. Koizumi, and H. Kanda, Appl. Phys. Lett. 85, 6365 (2004).

${ }^{5}$ J. Isberg, J. Hammersberg, E. Johansson, T. Wikström, D. J. Twitchen, A. J. Whitehead, S. E. Coe, and G. A. Scarsbrook, Science 297, 1670 (2002).

${ }^{6}$ T. Teraji, K. Arima, H. Wada, and T. Ito, J. Appl. Phys. 96, 5906 (2004).

${ }^{7}$ A. Tallaire, A. T. Collins, D. Charles, J. Achard, R. Sussmann, A. Gicquel, M. E. Newton, A. M. Edmonds, and R. J. Cruddace, Diamond Relat. Mater. 15, 1700 (2006).

${ }^{8}$ D. Takeuchi, H. Watanabe, S. Yamanaka, H. Okushi, H. Sawada, H. Ichinose, and T. Sekiguchi, Phys. Rev. B 63, 245328 (2001).

${ }^{9}$ N. Mizuochi, H. Watanabe, H. Okushi, S. Yamasaki, J. Niitsuma, and T. Sekiguchi, Appl. Phys. Lett. 88, 091912 (2006).

${ }^{10}$ S. Yamanaka, H. Watanabe, S. Masai, S. Kawata, K. Hayashi, D. Takeuchi, H. Okushi, and K. Kajimura, J. Appl. Phys. 84, 6095 (1998).

${ }^{11}$ L. S. Plano, in Diamond: Electronic Properties and Applications, edited by L. S. Pan (Kluwer Academic, Dordrecht, 1995), Chap. 3, p. 64.

${ }^{12}$ C. C. Battaile, D. J. Srolovitz, I. I. Oleinik, D. G. Pettifor, A. P. Sutton, S. 
J. Harris, and J. E. Butler, J. Chem. Phys. 111, 4291 (1999).

${ }^{13}$ H. Iwakuro, T. Kuroda, D. H. Shen, and Z. Lin, J. Vac. Sci. Technol. B 14 707 (1996)

${ }^{14}$ G. Ganguly, S. Yamasaki, and A. Matsuda, Philos. Mag. 63, 281 (1991).

${ }^{15}$ J. W. Lyding, K. Hess, and I. C. Kizilyalli, Appl. Phys. Lett. 68, 2526 (1996).

${ }^{16}$ J. Chevallier, F. Jomard, Z. Teukam, S. Koizumi, H. Kanda, Y. Sato, A Deneuville, and M. Bernard, Diamond Relat. Mater. 11, 1566 (2002).

${ }^{17}$ F. Fuchs, C. Wild, K. Schwarz, and P. Koidl, Diamond Relat. Mater. 4, 652 (1995).

${ }^{18}$ K. Kanaya and S. Okayama, J. Phys. D 5, 43 (1972).

${ }^{19}$ N. Mizuochi, H. Watanabe, J. Isoya, H. Okushi, and S. Yamasaki, Diamond Relat. Mater. 13, 765 (2004); N. Mizuochi, M. Ogura, H. Watanabe, J. Isoya, H. Okushi, and S. Yamasaki, Diamond Relat. Mater. 13, 2096 (2004).

${ }^{20}$ J. A. Weil, J. R. Bolton, and J. E. Wertz, Electron Paramagnetic Resonance (Wiley, New York, 1994).

${ }^{21}$ C. Glover, M. E. Newton, P. M. Martineau, S. Quinn, and D. J. Twitchen, Phys. Rev. Lett. 92, 135502 (2004).

${ }^{22}$ H. Watanabe, K. Hayashi, D. Takeuchi, S. Yamanaka, H. Okushi, and K.
Kajimura, Appl. Phys. Lett. 73, 981 (1998).

${ }^{23}$ S. G. Ri, H. Yoshida, S. Yamanaka, H. Watanabe, D. Takeuchi, and H. Okushi, J. Cryst. Growth 235, 300 (2002).

${ }^{24}$ C. S. Trevisan and J. Tennyson, Plasma Phys. Controlled Fusion 44, 1263 (2002).

${ }^{25}$ A. G. Engelhardt and A. V. Phelps, Phys. Rev. 131, 2115 (1963).

${ }^{26}$ H. Tawara, Y. Itikawa, H. Nishimura, and M. Yoshino, J. Phys. Chem. Ref. Data 19, 617 (1990).

${ }^{27}$ H. C. Barshilia and V. D. Vankar, J. Appl. Phys. 80, 3694 (1996).

${ }^{28}$ H. C. Urey, F. G. Brickwedde, and G. M. Murphy, Phys. Rev. 40, 1 (1932).

${ }^{29}$ M. Binnewies and E. Milke, Thermochemical Data of Elements and Compounds (Wiley, Weinheim, 2002).

${ }^{30}$ Landolt-Börnstein, in Thermodynamic Properties of Inorganic Materials, New Series, Group IV: Physical Chemistry, edited by W. Martienssen (Springer, Berlin, 2000), Vol. 19.

${ }^{31}$ S. C. Saxena and V. K. Saxena, J. Phys. A 3, 309 (1970).

${ }^{32}$ J. A. Kerr and D. W. Stocker, in CRC Handbook of Chemistry and Physics, edited by D. R. Lide (CRC Press, Boca Raton, 2000).

${ }^{33}$ C. G. van de Walle and W. B. Jackson, Appl. Phys. Lett. 69, 2441 (1996). 